\section{ERIC: a new governance tool for Biobanking}

European Journal of Human Genetics (2014) 22, 1055-1057; doi:10.1038/ejhg.2014.6; published online 5 February 2014

In 2009, the EU introduced a new governance tool for research, the European Research Infrastructure Consortium, commonly referred to as ERIC. On 22nd November 2013, an ERIC within biobanking research was established, the BBMRI-ERIC, with its seat in Graz, Austria. This article analyses what use the ERIC can be to researchers in biobanking, focusing on legal and ethical perspectives. Our conclusion is that the main advantages with the ERIC are its functions as a platform, creating opportunities for long-term cooperation between the Member States involved and their researchers. Within the platform, research groups can develop functional standards for technical, legal and ethical purposes, set up criteria for biobanks, and so on. The ERIC also creates a platform for the involved researchers to communicate with policymakers in the EU and the Member States. However, when it comes to addressing the diverse regulatory framework for biobanking in the $\mathrm{EU}$, one of the more important hurdles today, the ERIC does not provide for any substantial tools.

\section{BACKGROUND: WHAT THE EU CAN DO WITHIN THE RESEARCH AREA}

According to the principle of conferred powers, Article 5.2 Treaty of the European Union (TEU), the Union can only act within the limits of the competences conferred upon it by the Member States. Traditionally, the competences of EU have been focused on the building of an internal market, with free movement of goods, services, labor and capital. During the last decades, EU has also gained competences in policy areas such health and research. According to Article 179 Treaty of the Functioning of the European Union (TFEU), the EU has as its objective to achieve a European Research Area. In contrast to the establishment of the internal market, the competence of $\mathrm{EU}$ in the research area is more limited. This is reflected in Articles 180 and 181 TFEU where the EU is given competence to promote cooperation and to coordinate the activities of the Member States. In Article 4.3 TFEU, it further states that the exercise of EU competence shall not result in Member States being prevented from exercising theirs.

In practice this means that the work within the EU research policy area is carried out in different working groups or fora under the direction of the Commission, where representatives from the Member States collaborate with the Commission in developing programs and non-binding documents. One of them is the European Strategy Forum on Research Infrastructures, EFRSI, a Commission instrument to support a coherent and strategic policy for research infrastructures in Europe. The ESFRI identifies and describes the scientific needs for research infrastructures within the $\mathrm{EU}$ in the near future through roadmaps. (Three roadmaps have been published so far. ${ }^{1}$ ) The national competent authorities in the research area are represented in the ESFRI and the needs identified at the EU level will accordingly influence the priorities made at the national level. The BBMRI was one of the first projects to enter the European Research Infrastructure's preparatory phase of the ESFRI roadmap, funded by the Commission. ${ }^{2}$

The ESFRI roadmap addresses all scientific disciplines that require a large-scale Research Infrastructure with a joint effort on the European or international scale. In some cases, 'single sited' Research Infrastructures provide the best solution for the necessary research. In other cases, a 'distributed' Research Infrastructure is best suited from the scientific viewpoint as well as for the sustainability and optimization of partially existing resources. BBMRI-ERIC will be a distributed infrastructure.

The European Union further acknowledges the importance of joint European research infrastructures; according to Article 187 TFEU, the EU 'may set up joint undertakings or any other structure necessary for the efficient execution of Union research, technological development and demonstration programmes'. The ERIC is one example of such structure. In 2009, EU enacted a regulation setting out a legal framework of setting up a European Research Infrastructure Consortium (ERIC). ${ }^{3}$ The regulation enables the Commission to establish, on the application of at least three Member States, a consortium in form of an international organization where the Member States collectively can finance and manage research infrastructures. The aim of the ERIC is thus to create a platform where the Member States and their research institutions can cooperate and together build a research environment that is sustainable over time. In this way, the $\mathrm{EU}$ can create long-lasting and efficient conditions for European researchers that enable them to compete on a global research market.

\section{IMPLEMENTING RULES FOR BIOBANKING IN THE MEMBER STATES}

Another factor relevant in the analysis of the governance of biobanking in the $\mathrm{EU}$ is the division of competence in the implementation and enforcement of EU rules. The point of departure here is that the $\mathrm{EU}$ decides the rules; however, the Member States are responsible for implementing them. Even if the Member States have given up parts of their sovereignty when becoming members of the EU, it is still a matter for each Member State to decide on the internal infrastructure of the own state, to allocate the responsibility of different policy areas to public authorities, and so on. Further, Member States are also sovereign in relation to each other. One Member State cannot enact rules or adopt decisions that produces binding effect vis-à vis other Member States. This is a factor highly relevant for medical researchers working in the $\mathrm{EU}$; even if there might be some common rules, the point of departure is that each Member State is responsible for the implementation of the rules within its own national legal order. There are however exceptions to this main rule, cases where the EU in its secondary legislation has enacted rules laying down conditions for how national authorizes are to cooperate, share information as well as basic procedural rules on how to handle matters. For example, EU law may oblige the Member States to recognize each other's decisions within one specific area. This is the case with EU data protection, once the processing of a personal data has been deemed legal in one Member States, it may be processed freely within the entire EU. The difficulty arises from the many different interpretations of the Data Protection Directive within the Member States. German data 
may thus be processed in one way within the EU, Swedish data in a second way, Portuguese in an third, and so on (According to Article 4.1.a of the Data Protection Directive, it is the place of establishment of the controller who is decisive for pointing out the law applicable on the processing of the data. The controller is defined in Article 2.2 as the person or legal entity who alone or jointly with others determines the purposes and means of the processing of personal data.).

\section{THE ERIC AND THE QUESTION OF APPLICABLE LAW}

As set out above, the ERIC is an international organization established through a decision of the Commission on the application of at least three Member States. The ERIC is not an institution or an agency of the EU, nor is it part of the Member States. A relevant question is thus what law governs the activity of the ERIC. As stated above, the diverse regulatory framework for biobanking in the EU has been identified as an important hurdle for biomedical research in the EU (Report of the Expert Group on Dealing with Ethical and Regulatory Challenges of International Biobank Research, p. 40 and Kaye. $\left.{ }^{4}\right)$. The question is whether this situation can be addressed through the ERIC.

The ties between an ERIC and the EU legal system are strong. In Article 15 of the ERIC regulation, the legal acts relevant to the ERIC are listed; the setting-up and internal functioning of an ERIC shall be governed by EU law, in particular the ERIC regulation, and the decisions taken by the Commission to establish the ERIC, by the law of the State where the ERIC has its statutory seat, and lastly by the statutes of the ERIC and their implementing rules. Each ERIC must further report to the Commission and to the relevant public authorities, presumably the competent authorities in the Member States, on a yearly basis - Article 17.1 of the ERIC regulation. The Commission thus supervises the ERICs both regarding financial issues and the actual work of the ERIC.

The law applicable to the actual activities carried out by the ERIC will in the first hand be the law of the country where the ERIC has its seat, which in the case of BBMRI-ERIC means Austrian law. Regulations regarding internal administration, buying and running equipment and so on will be governed by this legal system. The choice of seat for the ERIC is thus important, as it also entails a choice of the applicable legal order. Regarding employment issues, tax, insurance and so on, the Article 10 of the ERIC regulation states that the statutes of the ERIC should include employment strategies, which in the BBMRI-ERIC will be drafted in the internal rules, enacted by the General Assembly (Articles 12 and 15, the Draft Statutes for the Biobanking and Biomolecular Resources Research Infrastructure European Research Infrastructure (BBMRI-ERIC).). In this area there is a possibility for the each ERIC to lay down its own rules within the limits of the law of the country where the ERIC has its seat, which may provide for competitive conditions for its employees.

However, this does not mean that Austrian law also will be applicable to activities of BBMRI-ERIC conduced in other states. The BBMRI-ERIC will have its seat in Graz, Austria; however, the biobanks connecting the ERIC will be distributed to the different national nodes coordinating the national biobanks. ${ }^{5}$ The law of the country where the activity is actually conducted will govern these activities. This issue is not clearly laid down in the ERIC regulation itself; however, in para 21 of the preamble it is stated that if the ERIC has a place of operation in another state, the law of that latter state should apply in respect of specific matters defined by the statutes of the ERIC.

\section{ADVANTAGES OF AN ERIC}

Today the ESFRI roadmap from 2010 has identified 13 Biological and Medical Science (BMS) research infrastructures and many of them are in the planning phase for an ERIC. But not all; for example, ELIXIR has chosen another path, a special project under the institutional framework of the EMBL organization (European Molecular Biology Laboratory, an organization that collaborates closely with other partners within biological research on long-term basis). That means that different BMS' will have different legal structures.

It follows from the foregoing that the biobanks connected to the BBMRI-ERIC as well as the other activities conducted within the ERIC, IT services, and so on, will continue to be governed by a multitude of different national regulatory regimes. The ERIC in itself does not have any mandate to change the regulatory framework applicable to the research conducted.

What may then be achieved by establishing an ERIC? No hard law solutions, but instead soft ones. The ERIC provides a platform for not only the researchers themselves but also their Member States to cooperate on a long-term basis, enabling the participants to develop tools for better navigation in the complex European legal landscape. First, the ERIC in itself facilitates the administration of the research infrastructure, the owning and running of equipment and the employment of staff, and not just for one research project at the time. Further, the ERIC creates a long-term setting within which the researchers involved may develop common standard for the biobanking activities and common criteria for the biobanks involved, as well as common legal and ethical tools. In practice, this type of standard setting is very valuable for future research and allows biobanks across Europe to function together. The ERIC is not in itself a necessary prerequisite for engaging in this development; however, the infrastructure creates a platform that is durable over time, allowing the researchers to build a functional framework for their present and future work. Further, the ERIC may in itself be an effective platform for influencing EU policies and a channel for communication between the ERIC and the relevant stakeholders within the European Research Area. The establishment of an ERIC can in itself be seen as recognition of the excellence of the research conducted within the project. As seen above, all the ERICs are to report to the Commission and to the relevant public authorities on a yearly basis. Since the ERIC regulation also established that the Commission should be assisted by a Comitology committee, in the form of a management committee (Article 20), this means that all Member States, not only the ones that are members of the ERIC, will be in direct contact with the ERIC. The importance of this channel of communication between the biobank world and the policy makers of the EU should not be underestimated. European administration is becoming more and more complex, with competing and conflicting interests competing for the attention of the decision makers. The enormous amount of lobbying activity caused by the proposed Data Protection Regulation is an illustrative example of this. The position of BBMRI-ERIC within the EU can create opportunities to explain and promote the specific interests of research vis-à-vis other policy areas - for example, data protection.

\section{CONFLICT OF INTEREST}

The authors declare no conflict of interest. 


\section{ACKNOWLEDGEMENTS}

This research was made possible by funding from the BBMRI.se infrastructure project financed by the Swedish Research Council, which had no influence on the design and content of this article.

Jane Reichel ${ }^{*, 1}$, Anna-Sara Lind ${ }^{2}$, Mats G Hansson ${ }^{3}$ and Jan-Eric Litton ${ }^{* 4}$

${ }^{1}$ Faculty of Law and Centre for Research Ethics and Bioethics, Uppsala University, Uppsala, Sweden; ${ }^{2}$ Faculty of Law and Centre for Research Ethics and Bioethics, Uppsala University, Uppsala, Sweden; ${ }^{3}$ Centre for Research Ethics and Bioethics, Uppsala University, Uppsala, Sweden;
${ }^{4}$ Department of Medical Epidemiology and Biostatistics, Karolinska Institut, Karolinska, Sweden E-mail: jane.reichel@jur.uu.se or jan-eric.litton@ki.se

1 The European Roadmap for Research Infrastructures 2006 updated versions 2008 and 2010. See on the Commission's webpage. [http://ec.europa.eu/research/infrastructures/ index en.cfm?pg=esfri].

2 ESFRI Roadmap for Research Infrastructures, Update 2008, and BBMRI.eu.

3 Council regulation (EC) No 723/2009 of 25 June 2009 on the Community legal framework for a European Research Infrastructure Consortium (ERIC).

4 Kaye J: From single biobanks to international networks: developing e-governance. Hum Genet 2011; 130: 377.

5 Article 1.9 and 3 of the Draft Statutes. 